\section{Infancia rural y trabajo productivo y reproductivo en el Valle de Aconcagua. Una mirada de género*}

Rural children and productive and reproductive work in the Aconcagua Valley. Analysis under the gender perspective

\section{Pamela Caro-Molina}

\section{Resumen}

El objetivo del artículo es reflexionar sobre las experiencias y representaciones sociales de niños y niñas rurales en relación al trabajo productivo agrícola y reproductivo doméstico, de una comuna rural del Valle de Aconcagua. Para ello se consideran los aportes del enfoque del protagonismo infantil y visibilización de

\footnotetext{
* Esta contribución se inscribe en el proyecto Fondecyt Iniciación №11140202, llamado "Significados y experiencias de la niñez y vejez como polos vitales de cuidado en familias del medio rural del Valle de Aconcagua. Una lectura desde la perspectiva de género". Agradecemos el apoyo del Programa Conicyt Fondecyt, por el financiamiento del proyecto.

** Investigadora Centro CIELO, Universidad Santo Tomás. pamelacaro1@santotomas.cl.
}

la voz de la infancia, así como la perspectiva de género y desigualdad. La investigación empírica recurrió a una metodología cualitativa, consistente en la realización de 39 entrevistas semiestructuradas a un total de 20 niños y 19 niñas de dos localidades rurales de la comuna de Putaendo. Se analizan relatos que evidencian el peso del trabajo en la construcción social de la infancia rural en el presente, la división sexual del trabajo en la niñez de medios rurales, la relación entre trabajo infantil, cansancio, cuerpo y dolor, y las representaciones y valoraciones acerca de éste.

Palabras clave: infancia, territorio rural, trabajo (productivo y reproductivo), género.

\begin{abstract}
The objective of this article was to reflect on the social experiences and representations of rural children from Aconcagua Valley as related to agricultural and household work. Focused considerations were given to the child protagonist approach and visibility of children's voice, as well as the gender perspective and inequality. This empirical research used a qualitative methodology, consisting of 39 semistructured interviews with 20 boys and 19 girls from two rural localities in Putaendo. The accounts evidenced the weight that work has on social construction of rural childhood, the sexual division of labor among rural children, the relationship between child labor, fatigue, the body and pain, and representations and valuations about that.
\end{abstract}

Key words: Childhood, rural territory, work (productive and reproductive), gender 


\section{Introducción}

El artículo aborda la relación existente entre infancia rural y trabajo, poniendo el foco en las características que adquiere en el presente, desde un enfoque de género, y estableciendo un contrapunto, desde la visión de la niñez, con cambios que se observan en relación al pasado. Entenderemos el concepto de trabajo desde una perspectiva amplia, a la que nos invita Heller (1970) que involucra tanto el trabajo productivo, realizado en el mercado laboral, que incluye por un lado la inserción, en el caso de medios rurales, en el mercado de trabajo asalariado agrícola y la producción campesina para la comercialización o autoconsumo, como así también el trabajo reproductivo realizado en el espacio doméstico privado, incluyendo los trabajos de cuidado.

La investigación base del presente artículo, de carácter más amplio, aborda los significados y experiencias de la niñez y vejez como polos vitales de cuidado en familias del medio rural del Valle de Aconcagua, haciendo un análisis desde la perspectiva de género. Abarca otras dimensiones, además del trabajo, que forman el entramado de las experiencias sociales de niños/ as y personas mayores rurales, que constituyen pivotes o pruebas societales (Martucelli 2007) en los procesos identitarios. El objetivo general de la investigación fue explorar desde una mirada holística, las actuales construcciones sociales de la niñez (y vejez) en territorios rurales, que se presentan discontinuos en procesos y relaciones con el pasado (Canales 2005: 33), expresadas en representaciones y prácticas, cruzadas por tensiones, arreglos y estrategias para encarar las exigencias actuales de cuidado. Buscamos respondernos a la pregunta por los significados de la niñez y vejez en medios campesinos y agrarios del presente.
El trabajo de campo fue realizado en el valle de Aconcagua, Valparaíso, específicamente en la comuna de Putaendo. Se optó por este territorio por ser una comuna de alta presencia de población rural, que supera el $57 \%$ (proyecciones INE 2012) y por convivir pequeña producción campesina con enclaves de producción de monocultivos orientadas a la exportación (carozos, uva y nueces). Entre sus características sociodemográficas destaca mantener tasas estables de población infantil, envejecimiento de la población, sobre todo femenina y creciente participación de mujeres adultas en el empleo asalariado agrícola estacional. En términos productivos es una comuna que basa su economía en la agricultura, con procesos de concentración de la tierra. También hay presencia de pequeña minería, comercio y servicios.

La hipótesis del artículo es que el trabajo constituye un pivote central en la infancia rural, con características diferenciales de acuerdo al género, con mutaciones y continuidadesalolargo de la historia, que se expresa en desigualdades, sociales y de género, encarnadas en los planos productivos como reproductivos. Sostenemos que a través del lugar que ocupa el trabajo productivo y reproductivo- en la infancia rural podemos comprender y conocer los procesos actuales de construcción social de la niñez, desde dicha prueba (Martucelli 2007).

El estudio se enmarca en un enfoque de derechos y reconocimiento de la visión y voces de los propios niños y niñas, alineado con la noción de protagonismo infantil (Cussianovich 2006). A partir de relatos en primera persona, pudimos problematizar las experiencias infantiles en relación al trabajo (productivo y reproductivo) con diferencias de género, así 
como las representaciones y significados del trabajo presentes en sus percepciones ${ }^{1}$.

Como parte de la revisión secundaria, contextualizamos la relación entre infancia y actividades vinculadas a trabajos productivo y reproductivo, obtenidos de la Encuesta de Actividades Niños, Niñas y Adolescentes 2012 EANNA- (Ministerio Desarrollo Social, Ministerio del Trabajo y OIT -Organización Internacional del Trabajo), considerando el nivel de macrozona centro, donde se sitúa Putaendo² ${ }^{2}$ estableciendo diferencias por sexo y zona de residencia (urbana/rural). El fin de recoger los principales hallazgos de esta encuesta es hacer dialogar en la discusión relatos cualitativos con información cuantitativa.

Dentro delos principaleshallazgosse presentarán las diferencias de género en la relación de niñez rural con el trabajo productivo y reproductivo; el peso del trabajo en la construcción social actual de la infancia rural; la división sexual del trabajo en la niñez de medios rurales; la relación entre trabajo infantil, cansancio cuerpo y dolor; las representaciones y valoraciones acerca del trabajo; y las principales diferencias entre prácticas actuales y pasadas, desde la perspectiva de la infancia.

Por razones de focalización en este artículo no se expondrán los resultados de las entrevistas a adultos/as y personas mayores de 65 años sobre la participación de la niñez en el trabajo. Por lo que el diálogo de experiencias y representaciones acerca de la relación infancia rural y trabajo, de niños/as con las generaciones mayores será abordado en otro trabajo.

2 Por características de representatividad de la muestra los datos serán analizados desde el nivel de macrozona.

\section{Revisión teórica y de fuentes secundarias cuantitativas}

\subsection{Infancia (in)visible}

La niñez ha sido una temática poco gravitante en los estudios sociales en general y casi inexistentes los abordajes en medios rurales, menos recogiendo percepciones, representaciones y prácticas de niños/as. En el caso de la historia de la infancia ha primado una perspectiva adultocéntrica, por lo que es necesario realizar un acto de justicia epistemológica y realismo histórico, que mire la historia y el presente desde los ojos de la niñez, quienes como sujetos sociales han sido poco estudiados, así como han sido ignoradas sus tensiones, contradicciones e identidades (Rojas 2010: 13; Salazar y Pinto 2002: 7-11).

Hallazgos indicativos del nuevo estatus y sentimiento hacia la infancia como construcción de la modernidad (Gélis 1994; Aries 1987) y aumento del "peso" de niños y niñas en las familias contemporáneas (Beck 1998: 154155), también se observan en las familias rurales (Caro 2016; Valdés 2009: 5). Estudios cualitativos previos concluyen que los/as niños/ as se han constituido en sujetos dialogantes y demandantes de padres comunicativos, se ha construido una preocupación por las decisiones que sobre ellos/as se tome y las actuales familias se han visto interpeladas a establecer "turnos" o arreglos de cuidado distintos a los del pasado (Castro 2012: 191-195). El PNUD señaló que la principal preocupación de las familias y las mujeres es la educación de sus hijos/as, para no repetir experiencias de trabajo infantil o aspirar a un trabajo más "aliviado" (2008: 61). En contrapartida, estudios anteriores evidencian que frente a la ausencia de soluciones estables 
de cuidado, niños y niñas rurales acompañan a sus madres, deambulando en huertos y predios, y dependiendo de la edad, juegan o bien se incorporan a las labores agrícolas iniciándose como niños/as obreros/as, en muchos casos con la venia de empleadores o contratistas, quienes los valoran toda vez que aportan a la producción y cosecha, siempre y cuando sean reservados y no "intrusos" (Caro 2016; Todaro y Reyes 2009: 40).

El nuevo estatus moderno de la infancia (Valdés 2009: 5) en la sociedad contemporánea, contribuye a comprender las transformaciones globales de la familia y parentalidad. La marginación histórica de la niñez en los registros oficiales de nuestra memoria, ha llevado a abordar la(s) infancia(s) como objeto(s) de sospecha (Salazar y Pinto 2002). Sin embargo, hoy estamos en un momento de especial sensibilidad sobre la niñez (Salinas 2001). En la historia de largo plazo, la emergencia del niño/a sujeto ha disuelto la antigua asociación del papel del genitor en el patrón de la virilidad tradicional, redimensionando y valorizando el lazo afectivo (Valdés y Godoy 2008: 84-107).

El reciente reconocimiento de la condición de sujetos de derechos se opone a su consideración como objeto de tutela por parte del Estado. Este enfoque considera a los/as niños/as "competentes" en la vida familiar y social, por lo que reconoce su derecho a participar, a ser escuchado e incidir en la construcción de la sociedad, en consonancia con la evolución de sus facultades, edad y madurez (Consejo Nacional de la Infancia 2015). En este sentido, la infancia ya no se asocia como en el antiguo régimen (Gélis 1994; Ariès 1987) al "aún no" (adulto/a) o al que "no habla" o "aunque hable, aun no razona bien" -significado etimológico de la palabra infante (Casas 2006). El reconocimiento social y progresiva visibilización de la infancia, está alineado con el actual enfoque del "protagonismo infantil" (Cussianovich 2006) que promueve dejar de mirar a los/as niños/as como propiedad de los/as adultos/as o como elemento peligroso privatizado de derechos.

\subsection{Trabajos y desigualdad de género}

El análisis del concepto de trabajo desde un enfoque de género implica reconocer como tal, tanto el que se ejecuta en el ámbito productivo, como en el reproductivo.

El trabajo productivo es aquel que se transa en el mercado, se considera en las cuentas nacionales (CEPAL 2007) y conlleva valor de cambio (Heller 1970). Constituye una prueba a través de la cual se construyen socialmente los individuos (Martucelli 2007) y el soporte privilegiado de inscripción en la estructura social por la fuerte correlación entre el lugar que se ocupa en la división social del trabajo y la participación en las redes de sociabilidad y sistemas de protección que «cubren» a los individuos ante los riesgos de la existencia (Castel 1997). Sin embargo, las transformaciones globales del trabajo, cuyas expresiones se exacerban en la agricultura, nos conducen a consignar que éste ya no cumple una función de integración. Por el contrario, estamos en presencia, en el agro, de un trabajo asalariado que se ha desregulado e hiperprecarizado (Castel 2009), afectando de manera particular a los sujetos que en él se insertan. En el caso del trabajo productivo por cuenta propia, las condiciones de producción también se han debilitado en medios rurales, especialmente por la pérdida de recursos 
productivos, entre ellos tierra y agua.

En la ruralidad, el concepto de trabajo productivo debería incluir las actividades que se realizan como ayuda familiar no remunerada que producen bienes y servicios para el autoconsumo de unidades domésticas (Belvis, Tarafa y Benach 2013: 22). El trabajo productivo como mecanismo social responde a necesidades de reproducción, por su función económica; de creación, por su función psicológica; y de colaboración y participación, en tanto función social. Los significados del trabajo revisten un doble carácter, ser un deber y al mismo tiempo un derecho (Maureira 2002: 121).

Las conceptualizaciones previas refieren a la inscripción de personas adultas al trabajo. La OIT conceptualiza como trabajo infantil a las actividades que ponen en riesgo la salud, integridad física y moral de niñas, niños y adolescentes -NNA-, según lo establece el Convenio 138. El trabajo infantil agrícola en zonas rurales, que incluye uso de herramientas pesadas, riesgo a la ergonomía y trabajo a la intemperie, entre otras características, está contemplado dentro de la categoría de trabajo peligroso, la cual a su vez está dentro de la tipificación de las Peores Formas de Trabajo Infantil (PFTI) (OIT 2015) ${ }^{3}$. Junto con los indicadores de "trabajo peligroso" y edad, el criterio "interferencia en la educación" cobra relevancia en su definición (Belvis, Tarafa y Benach 2013: 19).

Estudios en Chile indican que para los padres el trabajo infantil es una "ayuda" que los/as niños/ as realizan. Para los empleadores un "favor"

En términos generales se estima que en América Latina y el Caribe trabajan alrededor de 17 millones de niños/as. Un 70,4\% lo harían en actividades relacionadas con la agricultura, pesca, caza y silvicultura (OIT 2015). hacia los/as menores ya que con "esa platita pueden comprarse algo". Para los/as profesores es una realidad ignorada que pertenece al mundo privado de los/as niños (fuera de la escuela). Y para los/as niños/as, un recurso al cual le ven más ventajas que desventajas. Son el trabajador/a más "flexible" que existe en todo el espectro de trabajadores/as. Uno, porque su trabajo es mayoritariamente ocasional; dos, porque el salario, tiene más la forma de recompensa que de salario y tres, porque como sujeto de regulación es el más difícil, en tanto su trabajo es "invisible" (Silva y Damianovic 1998: 93).

Entenderemos por trabajo reproductivo aquel no remunerado realizado en el espacio doméstico, ligado al cuidado del hogar y miembros de la familia. Comprende la transformación de mercancías y mantención de espacios, atención de cuidado a niños/as, ancianos/as y enfermos/ as y realización de servicios de apoyo que unen las actividades del mundo público con el doméstico (Picchio, 2001; García y De Oliveira 2006, cit. en CEPAL 2007: 58). Tiene valor de uso, lo que significa que el producto es o puede ser usado por otros/as, satisfaciendo una necesidad social (Heller 1970).

Desde el análisis de género, es relevante cuestionar la histórica dicotomía público (productivo) - privado (reproductivo) que consolidó una valoración desigual a ambas actividades, considerando a las segundas, aunque acciones humanas necesarias, triviales y vergonzosas que requieren ocultarse, por eso son privadas; las primeras en cambio serían actividades vinculadas a la libertad y honor, que demandan, porque allí está su esencia, ser exhibidas públicamente para que puedan existir (Arendt 1993: 78). Las reproductivas se 
definen como actividades no especializadas, no asociadas al cambio sino a la recurrencia, que no exigen desplazamiento a espacios desconocidos, se asocian al sostenimiento de los vínculos y cohesión del grupo, implican una percepción del tiempo cíclico y no lineal, y son estructuralmente contrarias a la individualidad y poder (Hernando 2005: 125-130).

Investigaciones han problematizado respecto a la idea de que no todo niño/a realizando un trabajo es un trabajador infantil. Algunas labores son consideradas aceptables, o incluso "buenos trabajos", susceptibles de recoger ideas sobre el valor positivo asociado al trabajo de niños/ as y jóvenes en muchas culturas. Por ejemplo, tareas domésticas "ligeras", cuidado del jardín o cuidado de hermanos/as (Belvis, Tarafa y Benach 2013: 19). Estudios previos realizados en zonas rurales, evidencian que muchos niños/as declaran que deben ayudar a sus padres en las labores del hogar. Las niñas en los quehaceres domésticos, como hacer aseo, ayudar en la cocina o con el orden; y los niños en labores específicas del campo, como cuidar animales o ayudar en las siembras y cosechas (Silva-Peña et al. 2013).

En los noventa se registran estudios históricos sobre trabajo e infancia que abordan el fenómeno desde las consecuencias de la explotación que sufren niños/as (Rojas 1996). También se ha explorado una perspectiva que considera la actividad laboral infantil, en el contexto de un proceso más amplio de reproducción de las unidades familiares en situación de pobreza, así como de las características específicas del contexto de la economía regional y nacional, determinando la forma, oportunidad y características que asume el trabajo en la niñez (Maureira 2002: 113).
La articulación trabajo e infancia se recrea constantemente, según sea la relación que establece con otros fenómenos sociales. La inserción de la niñez en el trabajo es una realidad social antigua, sobre todo en espacios rurales. $Y$ aun cuando las tareas que realizan sean diferentes, el principio es el mismo, la realización de trabajo para el mercado asalariado o producción familiar se basa en la necesidad de contribuir económica o materialmente en los gastos familiares; y en el trabajo doméstico y de cuidado, para hacer posible la reproducción de la unidad familiar (Maureira 2002: 114). Por ende, se configura una relación entre participación infantil en el trabajo, en contextos rurales, vinculada a pobreza.

Estudios empíricos previos en Colombia, evidencian que la cultura de las familias rurales, es proclive al trabajo infantil, argumentada en la necesidad de formar niños/as responsables desde edades tempranas, evidenciándose la asociación entre trabajo infantil y pobreza (Hernández, Peña y Rubiano 2005).

Niños/as desarrollan experiencias diferenciadas en relación al trabajo productivo y reproductivo, de allí la relevancia del enfoque de género en el análisis. Esta categoría nos permite comprender que las relaciones y vínculos entre hombres y mujeres, de diversas edades, son formas primarias de relaciones significantes de poder (Scott 2008: 289), las que, a partir de discursos institucionalizados, fueron legitimando en la historia formas de desigualdad social (Tarres 2012: 385). Aplicada al análisis de fenómenos empíricos, nos permite desnaturalizar explicaciones determinadas en la biología (Hirata y Kergoat 1997), e implica reconocer que a través de procesos de socialización en las trayectorias vitales, vamos introyectado 
mandatos culturales, prácticas, símbolos, creencias, normas y valores sociales que se expresan en roles, tareas y responsabilidades que, de acuerdo a cada espacio y contexto, se consideran tradicionalmente masculinos 0 femeninos, formándose estereotipos, definiendo y prescribiendo modos y posibilidades de ser y hacer diferenciados para hombres y mujeres, incluso desde la primera infancia, que transcurre a lo largo de todo el curso de la vida (Lamas 2016: 420-421; Consejo Nacional de la Infancia 2015: 61).

\subsection{La evidencia de los datos de la encuesta de NNA}

La encuesta de Actividades de Niños, Niñas y Adolescentes (EANNA) aplicada el año 20124, nos entrega información relevante sobre la relación entre infancia y trabajo productivo y reproductivo. Desagregada por zona de residencia y sexo, considerando el nivel de macrozona centro ${ }^{5}$, muestra que de los 3.328 millones de NNA chilenos, 229 mil $(6,9 \%$ del total), trabajan en el mercado remunerado. De este grupo, la mayoría son hombres (69\%), y 4 de cada 10 tienen entre 5 y 14 años. El tiempo

A fin de disponer de información actualizada y relevante de Niños, Niñas y Adolescente -NNA-, el Ministerio de Desarrollo Social, en una acción coordinada con el Ministerio de Trabajo y Previsión Social y la Unidad de Estadísticas del Programa Internacional para la Erradicación del Trabajo Infantil (IPEC) de la (OIT, aplicó una encuesta, a una muestra de 9.978 niños/as de entre 5 a 17 años, que permite conocer las condiciones de vida de este grupo poblacional, a partir de sus propios relatos, y contar con un diagnóstico actualizado de la situación del trabajo infantil en Chile. Sus objetivos fueron "preguntar, consultar y escuchar" directamente a los NNA del país, recopilando información sobre magnitud, características y principales determinantes del trabajo infantil en Chile, lo que ofrece un diagnóstico actualizado de esta realidad (Observatorio social 2013).

5 Representatividad de la muestra que corresponde a las regiones de Valparaíso, O'Higgins, Maule y Biobío, donde se localiza la comuna de Putaendo. destinado supera en promedio el cuarto de jornada (16 horas a la semana), siendo mayor en hombres que en mujeres ( 2 horas) (MINDES 2013). Del número de NNA que declara trabajar, cerca de la mitad (46\%) vive en hogares del primer quintil de ingresos y más de un tercio $(36,6 \%)$ están en situación de pobreza, provenientes en su mayoría de hogares cuyas madres no alcanzan la educación media completa (60\%). En relación al trabajo reproductivo, la encuesta confirma la división sexual del trabajo, pues niñas en zonas rurales y urbanas realizan en mayor proporción tareas domésticas que niños.

Del total de trabajo productivo realizado por niños/as, éste se desarrolla en mayor proporción en zonas rurales. El 10,1\% de los/ as niños/as rurales forman parte de la fuerza de trabajo, lo que equivale a cerca de 42.000 niños/ as. Trabajan 11 horas promedio a la semana (también niños 2 horas más en promedio que niñas), pertenecientes mayormente al primer quintil. De ellos, 19.000 trabajan en la producción agropecuaria y sobre el $60 \%$ declara realizar alguna faena peligrosa, como uso de maquinaria, a la intemperie, con riesgo ergonómico o expuesto a plaguicidas.

Frente a la principal razón para trabajar, NNA plantean como prioridad la respuesta "por gusto" o "para tener su propia plata" (sobre el 58\%). En el caso de las niñas rurales la principal razón para trabajar es "para ayudar en los gastos de mi casa" (20,3\% de las niñas rurales de la macrozona centro). En relación a la temporalidad del trabajo, el $26 \%$ de niños y adolescentes rurales dice buscar empleo en las vacaciones del verano y un $18 \%$ de niñas, siendo más alto que en las zonas urbanas. Se reproducen los patrones tradicionales de 
género respecto a la participación en el trabajo remunerado, puesto que niños y adolescentes participan en mayor proporción que niñas en trabajos productivos. La tasa declarada más baja se da en niñas rurales, de 3,6\%.

La brecha de la distribución del uso del tiempo entre trabajo productivo y reproductivo comienza desde temprana edad. En el grupo de 5 a 14 años, encontramos una diferencia de 8 puntos porcentuales cuando destinan entre 1 y 7 horas al trabajo productivo a favor de los varones (65\% los niños y $57 \%$ las niñas), cuestión que se revierte cuando se destinan horas a las tareas domésticas (MINDES 2013). En particular la participación de las niñas y adolescentes es mayor que sus pares hombres en actividades vinculadas a la organización de las comidas. Por ejemplo, compras, poner la mesa o lavar los platos. La mayor participación reproductiva es en las niñas urbanas, y la menor en los niños rurales.

Las razones que esgrimen las niñas para participar en tareas domésticas es "para ayudara su familia", tanto en zonas urbanas como rurales. Por su parte, los hombres de zonas urbanas, en ambos niveles de alcance (macrozona y país), señalan hacerlo más "porque los mandan que por querer cooperar". Frente a la pregunta de qué quieren hacer cuando salgan del colegio, la respuesta más frecuente es que les gustaría trabajar. La tasa más alta se da en los hombres rurales a nivel nacional (58\%) y la más baja entre las niñas urbanas de la macrozona centro $(43,2 \%)$.

La encuesta muestra que niños rurales están más cerca de una visión tradicional acerca del futuro en relación a las niñas. Pues frente a las expectativas, si bien la mayoría abrumadora, y sin diferencias por sexo y zona de residencia relevantes, plantean que no quieren tener hijos/ as y formar una familia cuando salgan del colegio (tasa superior al 65\%), llama la atención que niños rurales son los que proporcionalmente más respondieron afirmativamente a la interrogante, es decir quisiera casarse y formar una familia al egresar (28\% de macrozona centro; y $29 \%$ nacional). Las niñas urbanas son quienes proporcionalmente más responden negativamente a la pregunta.

\section{Metodología}

La opción metodológica del estudio empírico fue de carácter cualitativa (Ruiz 2003; Tarrés 2004), en concordancia con una epistemología interpretativa hermenéutica (Gadamer 1977). Se justifica dicha opción en la medida que la base de los hallazgos fueron relatos, que develaron prácticas, percepciones, representaciones sociales, subjetividades y significados, las que fueron sometidas a un riguroso proceso de análisis.

Dado que la realidad social estudiada es plural, diversa, heterogénea y múltiple, accedimos a ella, a través de comprender lo que los testimonios de las entrevistas dicen, siendo totalmente receptivos, sin con ello autocancelarnos ni asumir una falsa neutralidad. Bajo la idea de Gadamer (1977: 332-333), de que la interpretación no se debe dejar imponer por ocurrencias propias, conceptos populares, posición, previsión y anticipación, sino que se elabora el conocimiento desde la "cosa misma", la tarea de la comprensión implicó elaborar planteamientos adecuados a lo observado, estando muy abiertas a los hallazgos que el material entregó. 
Los instrumentos de recolección de información fueron entrevistas semiestructuradas, en profundidad, individuales y en pareja, entrevistas grupales y observaciones no participantes. Optamos por la modalidad de entrevistas en profundidad, porque constituye un valioso instrumento de investigación para el acercamiento al campo de las prácticas y representaciones sociales. Fueron entendidas como una conversación cara a cara entre investigadora y niños/as que posibilitó acceder a las subjetividades, profundizar en temas de su realidad social (Vela 2004) y comprender sus perspectivas respecto a sus vidas cotidianas y experiencias, expresadas con sus propias palabras. Se optó por la condición de semiestructurada de la pauta para entrevistar a niños/as, la que se construyó como una guía de preguntas flexibles (Hernández, Fernández y Baptista 2010), que permitieron orientar la conversación. En el caso de los/as niños/as se aplicaron 22 entrevistas, 17 en parejas del mismo sexo (total 34 participantes) y 5 individuales. Participaron 20 niños en el estudio y 19 niñas, de entre 9 y 14 años $^{6}$. En las entrevistas se buscó levantar e interpretar los significados y sentidos que niños/as rurales otorgan a sus experiencias vitales, entre ellas las asociadas al trabajo productivo y reproductivo, y a las representaciones que construyen en torno a dicha prueba societal.

Las entrevistas en pareja fueron útiles para nivelar las relaciones de poder que pudieran haberse generado entre entrevistados/as y entrevistadoras y evitar así, la violencia

La gran mayoría de las entrevistas (salvo 2) se realizaron entre niños/as de los cursos 5to, 6to y $7 \mathrm{mo}$ básico, de las escuelas Alegría Catán de la localidad de Piguchén y del Liceo República de Estados Unidos de la localidad de Rinconada de Silva, en Putaendo. simbólica que pudiera producirse durante el ejercicio mismo de la entrevista (Bourdieu 1999). La instancia de preguntar en parejas permitió que los/as participantes dialogaran entre sí, comentaran y se hicieran preguntas entre ellos/as. La posibilidad de aburrirse durante la entrevista se aminoró. Recogimos de la experiencia, la importancia de dar espacio a que los/as niños/as hicieran preguntas a la entrevistadora, atendiendo a sus intereses y curiosidad. Cuestión que favoreció la confianza y fluidez de la conversación. La investigación cumple con los requisitos sobre consentimiento /asentimiento informado y comité de ética institucional. Se conserva así mismo el anonimato de los/as entrevistados/as.

\section{Análisis y discusión de los resultados}

\subsection{Centralidad y vínculo de niños y niñas con el trabajo productivo}

En las entrevistas constatamos el estrecho vínculo entre infancia y trabajo productivo, con diferencias de género y segmentado horizontalmente por sexo. En niños la relación se da principalmente con el trabajo agropecuario. La mayoría cuenta con experiencias laborales estacionales, como temporeros frutícolas con pago asalariado informal, o como trabajadores familiares no remunerados, en este caso más de manera permanente, apoyando el trabajo, en general, de padres o madres ${ }^{7}$. Superando con creces el $10 \%$ que señala la encuesta EANNA 2012 en medios rurales, lo que evidenciaría un subregistro de la participación en el trabajo infantil rural. Los entrevistados relatan que otros niños tienen experiencias como empaqueta-

Uno de los niños ayuda a su padre en un taller mecánico. 
dores en supermercados, o haciendo malabares en los semáforos, sin embargo, la retribución económica en la fruticultura es mayor (principal actividad económica de la comuna).

En las niñas, la inserción laboral se establece a partir del apoyo en trabajos por cuenta propia que realizan familiares, vinculados principalmente al comercio de productos agrícolas y no agrícolas (flores, helados o fruta en la feria), a actividades feminizadas como repostería y cuidado pagado, y en uno de los trabajos de mayor invisibilidad, con riesgos de auto-explotación, como es el partido de nueces de exportación a domicilio, función femenina que cumplen en compañía de sus madres en las casas. La tasa de participación es menor que los niños, así como el tiempo de dedicación al trabajo remunerado. Sin embargo, más de un tercio de ellas relató experiencias laborales intermitentes.

Niños de familias campesinas de serranías, propietarias de animales, son los que señalan trabajar de manera más activa y a más temprana edad, como un mandato familiar cultural incuestionable. Sin posibilidad de elección o negociación familiar. Sin embargo, no se observó un relato sacrificial o desde el malestar. Se plantea más bien como una realidad naturalizada en la que coinciden los niños de su entorno.

Siempre tengo que trabajar ... siempre que llego de la escuela tengo que ir a ver a las cabras que no se las coman los zorros y echarle el agua ... No me pagan, lo hago porque quiero ... como el niño que está allá al frente con el caballero, ese amigo tiene un campo que está no sé dónde, otro amigo y mi primo también ... Me levanto a las 6 (fines de semana), ayudo a sacar la leche o a veces tengo que levantarme a las 5 porque hay que ir a ver los caballos ... después me vengo para la casa me duermo un rato y me levanto, como y después me arreglo y voy con los perros para allá pal cerro a cuidar las cabras, vuelvo a almorzar y salgo de nuevo. En la tarde vuelvo, aunque pal cerro tengo una ruca, como una casita de piedra y ahí es donde me quedo cuidando las cabras todo el día (niño1, 10 años).

De los niños que trabajan en la producción familiar, algunos tienen pago y otros no. Uno de ellos, 12 años, recibe $\$ 2.000$ diarios de su padre por acarrear sacos de guano a las plantaciones. Considera que es un trabajo divertido. Valoración positiva que podría interpretarse porque hay un intercambio monetario de por medio.

La mayoría de los padres, madres y hermanos/as mayores son temporeros/as frutícolas, quienes, al igual que ellos/as, partieron como cosechadores, pero algunos ya son jefes de packing, control de calidad o contratistas (tienen furgón para trasladar temporeros/as a otras comunas, incluso regiones). Todos empleos estacionales, pero "mejores" en estatus y remuneración que ser cosechador/a. Algunos adultos/as trabajan en otras áreas productivas, conservando una segregación sexual tradicional. Los hombres en minería (estudiaron maquinaria pesada, y están en sistemas de turno fuera de la región) y las mujeres en salud o servicio doméstico.

De lo anterior, se colige que el trabajo productivo en los niños rurales es un campo naturalizado. En este territorio, de acuerdo a sus propios relatos, se "pelean" los cupos. Las niñas señalan que es común que los niños trabajen, "siempre trabajan para tener su plata y como son del campo ahí todos los hombres, chicos y grandes se los llevan para las cosechas... les pagan bien" (niña 1, 12 años).

En la comuna, el trabajo infantil no ha implicado deserción al sistema educativo, pero si una más lenta trayectoria educativa, manifestada en repitencias y atraso. En los niños, llama la atención que más de mitad de los entrevistados, 
es decir, 11 de 20 hayan repetido cursos de educación básica, algunos más de una vez. No ocurre lo mismo con las niñas. Las razones que esgrimen son bajo rendimiento, ausentismo por trabajo o enfermedad, o bien problemas de conducta. Pareciera ser que la condición masculina rural incidiera en "empujar" a los niños al trabajo remunerado, pero manteniendo la exigencia de asistencia a la escuela, sin notar que el costo recaería en la producción de niños con experiencias de frustración y fracaso escolar.

Es necesario reconocer que la relación entre infancia y trabajo es histórica en los contextos rurales. En las generaciones mayores, las mujeres principalmente como empleadas domésticas y nodrizas en fundos y haciendas; y los hombres como obreros y peones, de la agricultura o minería. Participaban desde tempranas edades en el acarreo de agua, cuidado de animales, siembra y cosecha de la familia o "patrón". Niños y niñas se iniciaban tempranamente en el servicio, a la patria, a través del servicio militar o a la patrona, a través del servicio doméstico (Caro 2016).

En el caso de la fruticultura, se identificó que los trabajos en los que se involucran niños incluyen la manipulación de cargas pesadas (capachos para cosecha de duraznos 0 damascos que pueden llegar a pesar entre 12 y 25 kilos), exposición a sustancias y agentes peligrosos como los plaguicidas o a condiciones ambientales perjudiciales para la salud como las altas temperaturas y sol, sin bloqueador solar, como testimoniaron. Evidenciando una condición hiperprecaria (Castel, 2009), de la inserción infantil laboral.

Iniciarse como temporeros en un huerto o packing a la edad de 12 o 13 años, como no es legal, creen que es una "concesión" que dan los empleadores. De acuerdo a la percepción de los propios niños, lo hacen porque "les tienen buena", es decir, les permiten la inserción laboral como una suerte de venia o favor. De lo que se puede colegir, que empleadores (muchos de ellos parientes) son encubridores y corresponsables de la inserción temprana al trabajo infantil en medios rurales. Cuestión que ocurre bajo la aceptación e incluso fomento parental.

\begin{abstract}
Donde vivo las personas grandes me tienen buena y hay un caballero que tiene un sobrino que es amigo mío y ellos me invitaron a trabajar (niño 2, 12 años); Me dejaban porque mi papá conocía al jefe, le había arreglado la moto y un camión y él le dijo que tenía pega para él y para dos personas más en los duraznos y me llevó a mi (niño 3, 13 años).
\end{abstract}

Se observaron dos formas de pago a niños que trabajan en la fruticultura. La menos habitual es que se les pague en forma directa por el trabajo realizado, en general a trato o destajo. Niños de 10 y 11 años por trabajar en la cosecha en un "buen día", lograron ganar $\$ 14.000$ y hasta $\$ 20.000$ diarios. La forma más habitual es que el dinero, sea intermediado por sus padres o madres, pues se trabaja en una cosecha familiar. En ese caso el dinero que reciben es menor ${ }^{8}$.

Niños que acompañan a realizar faenas en packing o plantas procesadoras, adquieren competencias tempranas. Por ejemplo, a los 14 años ya conocen a la perfección el proceso de calibrado, como cualquier operario de planta de proceso. De lo que se desprende que adquieren habilidades y ejecutan tareas que realizan adultos/as, pero sin la retribución que reciben los adultos/as.

Un niño de 11 años, describió recibir de su madre 20 mil pesos semanales por trabajar 4 horas diarias apoyándola en la cosecha de duraznos. 
Calibrar es una máquina que tiene 4 "cositos" se llama: el chico, mediano y grande y cuando ya va botando todo lo que tiene, ponen una caja para el "jumbo" entonces en una parte el huesillo baja y después se vuelve y cuando ya no puede más se saca la tabla y se pone en el mediano (niño 6, 14 años)

Las niñas que reciben pago por el trabajo productivo son menos que los niños; y los montos que reciben también son menores, visualizándose una brecha "salarial" en su desmedro, ya desde temprana edad. El destino del dinero de las niñas es variable. Algunas compran artículos personales de menor monto; otras financian demandas familiares como la compra de lo necesario para el período escolar. Una de las niñas usa los $\$ 2000$ pesos diarios que gana principalmente para dulces y cargar su celular (llamar a pololo). Otra para la satisfacción de necesidades básicas familiares, "porque a mi mamá todavía no le pagaban, entonces me tuve que hacer responsable de todo" (niña 3, 14 años).

A continuación, se sintetiza la participación por sexo en trabajos productivos, así como las modalidades de pago. De la tabla se desprende la existencia de una socialización temprana segregada por sexo (niños en producción agropecuaria y niñas en comercio, trabajo a domicilio y cuidado), con baja capacidad de negociación de ambos a nivel intrafamiliar, que implique por ejemplo negarse a trabajar.
Tabla 1. Matriz de división sexual del trabajo productivo de niños y niñas (10 a 14 años)

\begin{tabular}{|c|c|c|c|}
\hline \multicolumn{2}{|c|}{ Tipos de trabajos productivos } & \multirow[t]{2}{*}{ Niños } & \multirow[t]{2}{*}{ Niñas } \\
\hline $\begin{array}{l}\text { Actividad productiva } \\
\text { agricultura familiar }\end{array}$ & Modalidad de pago & & \\
\hline $\begin{array}{l}\text { Acarrear guano para } \\
\text { fertilizar tierra }\end{array}$ & $\begin{array}{l}\text { \$2.000 por día } \\
\text { (paga padre) }\end{array}$ & $x$ & \\
\hline Buscar caballos al cerro & Sin pago & $X$ & \\
\hline Cuidar cabras & Sin pago & $x$ & \\
\hline Alimentar animales & Sin pago & $x$ & \\
\hline \multicolumn{4}{|l|}{$\begin{array}{l}\text { Actividad productiva } \\
\text { mercado asalariado }\end{array}$} \\
\hline $\begin{array}{l}\text { Cosecha fruta } \\
\text { (temporero) }\end{array}$ & $\begin{array}{l}\text { A trato (individual } \\
\text { o mediado), hasta } \\
\$ 20.000 \text { diario }\end{array}$ & $x$ & \\
\hline Packing fruta (temporero) & $\begin{array}{l}\text { A trato (individual o } \\
\text { mediado) }\end{array}$ & $x$ & \\
\hline $\begin{array}{l}\text { Partir y seleccionar } \\
\text { nueces a domicilio } \\
\text { (temporero/a) }\end{array}$ & $\begin{array}{l}\text { A trato - saco } \\
\text { (mediado por } \\
\text { rendimiento familiar) }\end{array}$ & $x$ & $x$ \\
\hline $\begin{array}{l}\text { Plantas de deshidratado } \\
\text { de frutas (temporero) }\end{array}$ & $\begin{array}{l}\text { A trato } \\
\text { (individual o } \\
\text { mediado) } \\
\end{array}$ & $x$ & \\
\hline \multicolumn{4}{|l|}{$\begin{array}{l}\text { Otras actividades no } \\
\text { agrícolas }\end{array}$} \\
\hline $\begin{array}{l}\text { Ayudante mecánico (del } \\
\text { padre) }\end{array}$ & $\$ 10.000$ diario & $x$ & \\
\hline $\begin{array}{l}\text { Empaque de } \\
\text { supermercado }\end{array}$ & Propina & & $x$ \\
\hline $\begin{array}{l}\text { Venta ropa interior con } \\
\text { su madre (ambulante) }\end{array}$ & $\begin{array}{l}\text { \$2.000 por día } \\
\text { (le paga la madre) }\end{array}$ & & $x$ \\
\hline Venta flores & Pago & & $x$ \\
\hline $\begin{array}{l}\text { Venta manualidades en } \\
\text { plaza }\end{array}$ & Sin pago & & $x$ \\
\hline $\begin{array}{l}\text { Cuidando sobrina de dos } \\
\text { años (9AM a 24PM) }\end{array}$ & $\$ 3.000$ por día & & $x$ \\
\hline $\begin{array}{l}\text { Venta helados quiosco } \\
\text { abuela }\end{array}$ & Sin pago & & $x$ \\
\hline $\begin{array}{l}\text { Confección pasteles con } \\
\text { su madre }\end{array}$ & Sin pago & & $x$ \\
\hline $\begin{array}{l}\text { Venta en la feria (con } \\
\text { padres o abuelos/as) }\end{array}$ & Sin pago & & $x$ \\
\hline
\end{tabular}

Fuente: Elaboración propia 


\subsection{División sexual del trabajo en la niñez de medios rurales y su expresión en la reproducción social}

Constatamos que en medios rurales como el estudiado, con procesos de inserción femenina en el trabajo agrícola y productivo, tanto niños como niñas participan en tareas domésticas y reproductivas, con diferencias de género en la intensidad, y variaciones, de acuerdo a la composición de las familias y al lugar que ocupen en ella.

Una primera evidencia es que las niñas siempre hacen tareas domésticas y reproductivas, incluyendo el cuidado de otros/as. En cambio, los niños solo "a veces", de manera menos activa. La participación de ambos está mediada por la presencia/ausencia de la madre, pues para la generación adulta, la responsabilidad doméstica sigue siendo femenina. Es decir, si ellas están, hacen las tareas con baja ayuda.

Cuando hay grupos de hermanos/as mixtos, son las niñas en quienes las madres delegan las tareas domésticas, manteniéndose una transmisión intergeneracional tradicional de los roles de género, con baja capacidad, sobre todo de las niñas, de tomar decisiones sobre las labores a ejecutar, pues existe un mandato que se reproduce a modo de habitus de género (Bourdieu 2000), de manera casi irreflexiva, como parte de la habitualidad de ser niña. Sus hermanos (mayores) son descritos por ellas como "flojos", descuidados y problemáticos. En estas experiencias familiares, destacan que las madres consienten $o$ avalan la menor participación masculina infantil en labores reproductivas. Delegan las funciones domésticas y de cuidado a los niños, sólo frente a la ausencia femenina infantil, como una suerte de "reemplazante" de la figura femenina de cualquier edad, esto es cuando no hay niñas entre los/as hermanos/as o el entrevistado es el hermano mayor.

Todas las niñas entrevistadas se reconocen involucradas y socializadas en el trabajo doméstico, realizando las más diversas labores, sin cuestionamientos. "Cuando mi mamá sale a trabajar y no hay nadie en la casa y tengo que hacer todo el aseo, camas, barrer, lavar la loza, ordenar" (niña 4, 12 años).

Como trabajo en el ámbito doméstico familiar campesino, niños realizan tareas vinculadas a la alimentación de animales, algunos domésticos (perros, gatos) y otros de pequeña producción animal (gansos), haciéndose en este caso difusa la frontera entre labor reproductiva y productiva.

Como un designio, las niñas tienen normalizada desde temprana edad su participación doméstica. No hay reclamos en general. Sin embargo, también observamos en algunos niños una actitud positiva frente al rito doméstico. La justificación es que lo hacen por diversión.

\footnotetext{
Hago aseo, a veces cuando estoy aburrido, por ejemplo, veo la casa desordenada y empiezo a ordenar, a veces ella (mamá) está enferma, le hago las cosas, té ... me gusta hacer aseo, es que soy limpiecito, no hay ninguna cosa que no me guste hacer en la casa (niño 4, 12 años).
}

Niños y niñas participan en el cuidado de hermanos/as menores, reemplazando a sus madres, incluyendo labores como mudar o alimentar. Niños expresan contradicciones cuando reflexionan, pues les delegan a ellos (11 años) funciones de cuidado de sobrinos más pequeños (2 años), lo que viven con congoja pues declaran sentirse desplazados del cariño y atención que su propia madre y hermanas 
mayores le brindaban a él, antes del nacimiento de sus sobrinos, auto percibiéndose como poco importantes dentro del núcleo familiar. De lo que se desprendería una falta de percepción femenina adulta frente a demandas emocionales que puedan presentar niños de 11 años.

\begin{abstract}
Antes que nacieran el Emilio y el Gaspar (sobrinos) mi mamá me pescaba, pero ahora que están ellos, no me toma casi en cuenta... lo hago de tonto (portarse mal en el colegio) o para que se rían de mí, para que me "pesquen", porque en mi casa no me "pescan" (niño 8, 11 años).
\end{abstract}

Adicionalmente consideran que es muy alta la responsabilidad de cuidar a bebes, por los riesgos que significa. "Me dejan cuidando a las "guaguas", pero no me gusta porque si pasara algo me retarían a mí y no quiero eso" (niño 8, 11 años).

Quienes pasan más tiempo en las casas son justamente niños/as y abuelas (abuelos sobreviven menos). Niñas, en mayor proporción que niños, cuidan de abuelas mayores de 75 años que requieren cuidados. Lo más complejo de cuidar a adultas mayores es tratar con su carácter, "son enojonas", más que lidiar con las tareas, como darles las medicinas. El cuidado como deber infantil femenino podría actuar como factor de rezago escolar, puesto que las niñas señalan que dejan deberes escolares por tener que dedicarse al cuidado de personas mayores.

La opinión de las niñas de que sus madres trabajen remuneradamente es ambivalente. No así de sus padres, reproduciéndose el valor desigual proveniente del patrón tradicional de padre proveedor. Esto porque observan que la salida de las adultas al mercado asalariado genera tensiones familia y trabajo que recaen en ellas (niñas), estando obligadas a resolverlas, con baja capacidad de negociación. Aunque reconocen que las madres también recurren a vecinas o amigas, por ejemplo, para enfrentar el cuidado de hijos/as menores de 12 años y así encarar dicha necesidad. Esto se produce en contextos de baja participación masculina adulta, es decir, baja corresponsabilidad, así como baja presencia de soluciones de cuidado estatales (salas cunas o jardines infantiles).

Como se observa en la matriz de división sexual del trabajo reproductivo en la niñez, en las entrevistas se evidenció que niños aun cuando participan en una diversidad de tareas domésticas y familiares, siempre con menos intensidad, existen actividades de las que se excluyen, como cocinar, lavar ropa y limpiar baños.

Tabla 2. Matriz de división sexual del trabajo reproductivo de niños/as (10 a 14 años)

\begin{tabular}{|l|c|c|c|c|}
\hline \multirow{2}{*}{$\begin{array}{l}\text { Tipos de trabajos } \\
\text { reproductivos }\end{array}$} & \multicolumn{2}{|c|}{ Niños } & \multicolumn{2}{c|}{ Niñas } \\
\cline { 2 - 5 } & Siempre & A veces & Siempre & A veces \\
\hline Comprar pan & $\mathrm{X}$ & & $\mathrm{X}$ & \\
\hline Hacer aseo & & $\mathrm{X}$ & $\mathrm{X}$ & \\
\hline Lavar la loza & & $\mathrm{X}$ & $\mathrm{X}$ & \\
\hline $\begin{array}{l}\text { Alimentar animales } \\
\text { domésticos }\end{array}$ & $\mathrm{X}$ & & $\mathrm{X}$ & \\
\hline Ordenar & & $\mathrm{X}$ & $\mathrm{X}$ & \\
\hline Barrer & & $\mathrm{X}$ & $\mathrm{X}$ & \\
\hline Hacer camas & & $\mathrm{X}$ & $\mathrm{X}$ & \\
\hline Sacar la basura & $\mathrm{X}$ & & $\mathrm{X}$ & \\
\hline Cocinar & & & $\mathrm{X}$ & \\
\hline Lavar y recoger ropa & & & $\mathrm{X}$ & \\
\hline Limpiar baño & & & $\mathrm{X}$ & \\
\hline
\end{tabular}




\begin{tabular}{|l|c|c|c|c|}
\hline $\begin{array}{l}\text { Cuidar niños/as } \\
\text { (familiares) }\end{array}$ & X & $x$ & \\
\hline Cuidar a abuelas & & $x$ & $x$ & \\
\hline $\begin{array}{l}\text { Cuidar a vecino } \\
\text { o sobrina con } \\
\text { discapacidad }\end{array}$ & & $x$ & $x$ & \\
\hline
\end{tabular}

Fuente: Elaboración propia

\subsection{Relación entre trabajo productivo/ reproductivo infantil, cansancio, cuerpo y dolor}

Pudimos identificar que la participación de niños en la fruticultura industrial del valle se realiza en todas las fases del proceso, principalmente cosecha, pero también en selección en packing, en plantas de deshidratado (pasas) y a domicilio en labores de proceso como partir nueces para la exportación? ${ }^{9}$. En los tres primeros casos, expuestos a carga pesada para su edad y cuerpos, y a condiciones ambientales y sanitarias hiperprecarias como el resto de los/as trabajadores/as, caracterizadas por la exposición al sol sin protección en las horas más dañinas del día, ausencia de baños higiénicos y no disposición de agua potable para beber.

Las principales dolencias que reconocen los niños por el trabajo temporal es dolor de hombros, brazos y espalda "al levantar, cortar y limpiar, ... estar agachado, es muy cansador" (Niño 9, 12 años).

\begin{abstract}
Trabajé cortando duraznos, allá en Los Andes, me llevó mi papá, ganaba 20 mil diarios. Entraba a las 8 y salía a las 4. Era muy cansador. Teníamos esa "cosa" (capacho) y teníamos que andar trayendo en la espalda. Al otro día me sentía adolorido, me dolía mucho el cuerpo y tenía un desgarro en el brazo (niño 3, 13 años).
\end{abstract}

La selección implica dejar separadas nueces de acuerdo a la calidad -cuarto, mitad, entera, mariposa-.
Niños no insertos en el trabajo frutícola, tienen una visión negativa por los costos en la salud física, y han logrado ejercer el derecho a no participar en el trabajo, negociado con sus padres/madres. "Es muy esforzado, por ejemplo, estar al sol para un niño es malo, por eso yo no salgo a trabajar en esas cosas, no me gusta mucho" (niño 4, 12 años).

También niños que trabajan en producciones familiares, son explícitos en señalar las dolencias que le afectan por la rudeza del trabajo que realizan. "Uno se cabrea y a mí me dolían hasta las caderas por eso" (niño 1, 10 años). Así mismo relatan riesgos a los que han estado expuestos producto de la participación en faenas campesinas, que califican como "trabajo peligroso", tal como lo ha tipificado la OIT.

Me corneó un toro, yo era chico (ahora tiene 10 años) y fui a darle comida y no sé qué le pasó estaba enojado y estaba al lado y me toreó y salté por arriba de la cerca y caí arriba de los palos... salté y caí arriba del toro agarré un palo y quedó medio aturdido (niño 1, 10 años).

Aún así, no todos formulan juicios negativos hacia la acción de trabajar. Consideran que es una forma de colaborar con sus padres, a quienes también les resulta extenuante el trabajo en el campo. Son los que declaran que el trabajo a ellos "no los cansa". Sino que más bien lo asocian a un juego, lo hacen por diversión, para "sacarse el aburrimiento". Sin embargo, solo cuando éste se realiza por un período acotado de tiempo y fuera del período escolar. "Me subía a los árboles y me gusta hacerlo, siempre lo hago" (niño 10, 12 años). Dicha asociación lúdica con el trabajo agropecuario también podría responder a la naturalización de la infancia masculina con su propio mandato social sexual, relacionado con el rol proveedor. 
Las tareas reproductivas de las que más reniegan los/as niños/as son las vinculadas al cuidado. Niños (11 o 12 años) se cansan de cuidar niños (pequeños de 2 o 3 años son inquietos). Niñas se quejan de tener que cuidar a abuelas, porque el desgaste emocional, también les cansa. Son pocos los niños que señalan que cuidar a hermanos/as menores es una actividad "relajada", pues lo complementan con descanso. Esto ocurre cuando se trata del cuidado de niñas de entre 6 a 10 años. "Total yo me pongo a jugar con el computador y ella se acuesta en la cama de mi mama y empieza a ver tele y no es tanto trabajo" (niño 6, 14 años).

\subsection{Diferencias de género en las representaciones y significados del trabajo}

En niños y niñas se reproduce la invisibilización del trabajo doméstico como trabajo. "Mi mamá no trabaja, es dueña de casa no más" (niña 8, 11 años); "Mi papá trabaja y mi mamá hace las cosas de la casa" (niño 3, 13 años). Dicha ausencia de reconocimiento también se traspasa a las tareas que realizan las niñas en el plano reproductivo. Pues, a pesar que son ejecutoras de tareas domésticas, no se reconoce aquello como trabajo.

En el caso del trabajo productivo que realizan niños y niñas rurales existen percepciones y valoraciones diversas, con diferencias de género.

Es más generalizada la opinión de las niñas respecto a que la educación es más importante y prioritaria que el trabajo productivo precoz, no estando de acuerdo con el ingreso temprano a actividades asalariadas en el agro. "Pienso que deberían terminar sus estudios primero" (niña 2, 11 años). Respecto a la mirada de futuro, consideran que las personas que no estudian tendrán trabajos más duros físicamente, realidad de la que se quieren distanciar. Las expectativas de la mayoría de las niñas son estudiar en la universidad, siendo más elegidas, en orden de preferencia, las carreras de veterinaria, policía de investigaciones, medicina y enfermería. Los niños mencionan en menor proporción querer estudiar en la universidad. Se proyectan en carreras técnicas como computación y mecánica, mencionándose también en alta frecuencia el interés por ser futbolista profesional. No todos piensan seguir estudiando, algunos se visualizan trabajando apenas salgan del liceo. De lo anterior, se colige una mayor aspiración infantil femenina rural vinculada a la educación superior, cuestión que se confirma con los datos de matrícula por sexo (en 2017 el 52\% de la matrícula de educación superior fue de mujeres a nivel nacional). ${ }^{10}$

Para las niñas, seguir estudiando una carrera profesional, se justifica por la aspiración de alcanzar autonomía económica. "Quiero estudiar una carrera para así no depender de nadie" (niña 1, 12 años).

Respecto a la valoración o "juicio moral" en torno al trabajo productivo en la niñez, se observan opiniones ambivalentes en las voces de las niñas. Algunas plantean que se debe considerar y respetar el deseo de los niños. Por ningún motivo obligarlos a trabajar, pero autorizarlos si ésta es su intención, pues así pueden adquirir los bienes que aspiran, como celulares o tecnología. "Si ellos no quieren y sus padres los obligan, eso sería injusto, pero si ellos quieren y sus padres los dejan no sería injusto" (niña 6, 11 años). No obstante, si tiene menos

\footnotetext{
http://informeget.cl/juventud/. Visitada 01/04/2018
} 
de 10 años y el trabajo es fuera de la agricultura, lo cuestionan. "Un niño que no debe haber tenido ni diez años, estaba vendiendo parches curitas y esa vez a mí se me rompió el corazón" (niña 4, 12 años). Una de las niñas se manifiesta contraria a la ley que prohíbe el trabajo infantil porque impediría alcanzar la aspiración de autonomía económica previamente esbozada, "no me gusta tanto así el derecho, porque no puedo hacer casi nada" (niña 9, 13 años).

Las niñas reconocen que las familias las protegen más a ellas que a los niños para el ingreso al mercado asalariado informal, por las extremadamente precarias condiciones sanitarias y ambientales. En este estudio no encontramos niñas trabajando como temporeras en plantaciones o packing, en cambio de los 20 niños entrevistados, 11 tienen experiencias de trabajo productivo, de ellos siete como temporeros de la fruticultura. Con ello se conservan las visiones tradicionales polares respecto a la asociación mujer-trabajo doméstico y hombres-trabajo asalariado. "Mi mamá no me deja porque dice que es muy sacrificado... mis primos cuando llegan, llegan todos sucios, rajuñados, asoleados" (niña 7,14 años).

Incluso algunas han querido trabajar como temporeras, pero se arrepienten por la dureza física evidente del trabajo. Probablemente también porque se proyectan en un futuro fuera de la agricultura, en mayor proporción que los niños.

Quise una vez, pero después me arrepentí, porque era mucho trabajo... es cansadora, cuando uno es temporero, los árboles son grandes, entonces tienen que andar con una escalera, el capacho, y es agotador (niña 3, 14 años)

La visión de los niños respecto a la valoración del trabajo infantil es distinta a las niñas. Sin embargo, no hay opiniones generalizadas, sino que depende si sus experiencias son en el trabajo asalariado o en la producción agrícola familiar. Lo que no está mediado exclusivamente por la existencia de remuneración.

Para aquellos que están insertos en la producción familiar, trabajar siendo niño (10 años), pero "no tan niño", es visualizado como una forma de adquirir aprendizajes para la vida adulta masculina en el campo. Confirmando que niños se proyectan más que niñas a una vida futura vinculada a labores campesinas.

Ahora que no soy tan niño empiezo a hacer cosas para que cuando sea grande sepa que hacer, porque ahora yo voy con mi abuelo a bajar las vacas (niño 1, 10 años).

Algunos aceptan y valoran el trabajo como temporeros. Están de acuerdo en que los niños de su edad trabajen, para tener dinero para comprar sus "cosas" y se reitera la idea que es para no aburrirse en las vacaciones. Sin embargo, otros piensan que el trabajo infantil les impide seguir estudiando, o tener mejor rendimiento. Consideran que podrían comenzar a trabajar desde los 15 años, no antes. Si tienen menos de esa edad, desde los 13 , deberían estar acompañados de un adulto para protegerlos frente a riesgos. Es decir, estos niños son conscientes de los peligros a los que se los expone en el empleo temporal.

Lo malo de que los niños trabajen es que están muy jóvenes, no disfrutan... como jugar a la pelota, estar con los amigos... no disfrutan la niñez, que uno se divierte (niño 7, 13 años).

Se encontró pocos relatos de niños que, a pesar de la invitación e insistencia paterna para ingresar al trabajo de temporero, prefieren orientarse a sus estudios. 
A veces mi papá me dice que en verano si es que me aburro puedo ir a ayudarle a llenar los bines de uvas o duraznos, me darían 10 lucas o 15, me dice que si en verano yo tengo tiempo podría ir y lo podría ayudar a su trabajo y allí lleno los bines y me paga.... Me gustaría, pero me interesan más los estudios (niño 11, 12 años)

Los niños tienen la certeza que sus padres y madres apoyan e incentivan a que trabajen remuneradamente. Perciben incluso que son más valorados si lo hacen, y logran notar el orgullo que sienten por ello. Confirmándose lo señalado por la literatura (Hernández, Peña y Rubiano 2005), que los padres aspiran a formar niños/as responsables desde edades tempranas a través de su inserción al trabajo.

Me apoyaba harto porque entraba a las 8:30 y él me levantaba a las 7, me daba desayuno, me hacía bañar y me buscaba la ropa y todo, era como que me alababa porque estaba trabajando (niño 3, 13 años)

Entrevistados que ya habían cumplido 15 años (no considerados en la muestra para este artículo) sostienen que el hecho que niños trabajen es un "abuso de poder", pues no tienen libertad para negarse a trabajar, reciben el mismo (mal) trato que los/as temporeros/as adultos/as y no tienen las mismas posibilidades para defenderse, percibiendo una vulneración de derechos

Joven 1: Porque se aprovechan, y la infancia es lo más corto, y a usted lo miran y le dicen ya a ponerse las pilas y seguir trabajando. Lo mandan a trabajar y él no quiere. Tienen el mismo trato de un adulto. Le exigen como a un adulto (15 años)

Joven 2: Creo que peor que un adulto. Porque te pueden decir de todo, porque saben que un niño no se va a defender de un adulto (15 años).

\subsection{Presente y pasado en las prácticas de la infancia rural}

Desde la visión de la niñez actual, existen diferencias en las prácticas asociadas a la relación infancia y trabajo, lo que se observa a través de los siguientes aspectos.

Primero, la intensidad y continuidad de su participación en el trabajo. La inserción infantil al trabajo productivo en las generaciones anteriores (padres y abuelos) se establecía como un continuo y una forma temprana de "término de la niñez" y paso a formas de vida adulta. En cambio, en el presente, la incorporación es más bien elástica, pues los niños entran y salen del mercado de trabajo asalariado temporal, siendo intermitente y estacional su calidad de participación.

Segundo, la deserción escolar. En el pasado el trabajo infantil (agrícola y patronal doméstico en el caso femenino) fue un motor de expulsión de niños y niñas de la escuela. En cambio, en el presente, no ocurre la misma realidad, pues tanto padres/madres como niños/as visualizan en la educación (escolar y superior) un vehículo de movilidad social, y no sólo se mantienen en la escuela por la "obligatoriedad" que impone el Estado, sino que, sobre todo está presente en el discurso de las niñas, la idea de que acceder a mayor educación permitirá romper con designios tradicionales femeninos, como el matrimonio y la maternidad. Cuestión que es consistente con lo señalado en el informe PNUD 2008, como aspiración familiar, y con la tendencia de las respuestas femeninas en la encuesta EANNA, que muestra a las niñas menos conservadoras que los niños.

Si bien, hay trabajo infantil, la permanencia escolar está por sobre el trabajo. Ahora bien, las 
consecuencias negativas de hacer ambas cosas (trabajar y estudiar) en el caso de los niños, son el lento progreso escolar y reducción de las expectativas en la continuidad de estudios, pues en sus propias palabras, "les queda gustando" ganar su propia plata a temprana edad.

Tercero, el destino de los ingresos es distinto. En el pasado la inserción laboral infantil estaba menos salarizada, su trabajo era un aporte al ingreso monetario y no monetario familiar, y los niños no decidían sobre el devenir del dinero que generaban, el que en general recibían de manera directa sus padres. En cambio, en el presente, cuando los niños reciben pago directo o intermediado, lo destinan más a satisfacer necesidades personales y toman decisiones sobre su uso.

Por ejemplo, lo usan para comprarse artículos de consumo, como teléfonos, zapatillas de marca, ropa, y otros necesarios para la asistencia escolar, que sus padres no pueden comprar por los bajos ingresos que tienen y porque son familias numerosas. También la ocupan para comprar "cosas ricas" para comer en la casa o fuera, pagar entretenimientos o gastarla en una fiesta tradicional, tipo carnaval, que se hace todos los febreros en Putaendo llamada "La Chaya", que dura nueve días seguidos con shows y venta de comidas y productos.

Me compré un teléfono porque mi papá no podía gastar plata, porque somos muchos, somos 8 en total, 5 niños que van al colegio, y también me compré zapatos (de colegio), estos que tengo puestos (niño 5, 14 años).

La globalización de los medios de comunicación y el acceso a publicidad e información ha modificado las preocupaciones infantiles del presente en relación al pasado. En la actualidad, se reconoce la existencia de una excesiva atención de niños y niñas rurales por la presentación personal. Antes las familias confeccionaban lo que ahora se compra en el mercado; cuestión que va aparejado de una mayor monetarización de la vida campesina en relación a las generaciones pasadas.

En el plano simbólico de las relaciones intrafamiliares, se observa en niñas y niños rurales del presente una demanda antes menos presente, por opinar en el seno familiar, tensionándose con las visiones actuales adultas, que esperan un comportamiento más sumiso, como el que tuvieron ellos/as en su etapa de niñez pasada.

La continuidad entre pasado y presente, en la relación infancia y trabajo, se hace más visible en niños que en niñas. Un primer aspecto que se mantiene, es que aun cuando la tecnología ha alivianado la rudeza del trabajo agrícola, la exposición a riesgos permanece, pues desde temprana edad manejan maquinarias y equipamientos de uso adulto. $Y$ un segundo aspecto de continuidad está vinculado al sentido de arraigo al campo y paisaje agrícola, que se hace evidente en los discursos masculinos, al preguntarles por el valor que reviste trabajar en faenas agrícolas.

Comparando el papel de la niñez en el trabajo doméstico, se mantiene la tendencia social de asignar labores de cuidado de familiares dependientes principalmente a las niñas. Sin embargo, lo que ha cambiado son las actitudes femeninas de la niñez frente a dicho mandato. En la actualidad, las niñas declaran ser menos dóciles frente ala tarea asignada, evidenciándose una resistencia cultural y reclamo en su grupo familiar por tener que dedicar tiempo a dichas responsabilidades. 


\section{Conclusiones}

Los resultados de la investigación muestran que, en la ruralidad, el trabajo productivo y reproductivo, sigue estando en el centro de la construcción social y cultural de la infancia, con diferencias de género. La gran mayoría tiene experiencia en la fruticultura, cosechando, en parcelas de parientes o acompañando a padres y/o familiares a fundos o huertos, desde los 11 años, entre los meses de noviembre y marzo. También hay niños que, desde los 10 años cumplen funciones de arrieros a nivel de producción familiar campesina, que no tiene carácter estacional, sino que se realiza todo el año, con intensidad los fines de semana y vacaciones.

Una de las distancias que presenta el trabajo en los/as niños/as con las generaciones anteriores (padres/madres y abuelos/as), es la estacionalidad del trabajo, principalmente de niños temporeros de la fruticultura, y la complementariedad del trabajo con la educación, pues no abandonan o desertan, aún con evidentes rezagos en niños, más que en niñas, que se manifiesta en la recurrencia con que repiten de curso. Los relatos de los niños evidencian diferencias entre las exigencias actuales y pasadas en torno al trabajo infantil. Señala que en la actualidad a los niños se los "esclaviza" menos, y se presentan discursos desde la niñez favorables al ejercicio de nuevos derechos.

En términos culturales se observan diferencias entre trabajar en la producción familiar (agrícola y no agrícola) y en el trabajo asalariado agrícola. Las razones del ingreso al trabajo productivo en actividades por cuenta propia familiares (agrícola, comercio, producción de alimentos) se asocian más a un proceso de formación cultural (cuidar cabras, vender en la feria) e integración a la familia y comunidad. En el caso de los niños temporeros, la inserción en enclaves agroproductivos industriales está asociada a precariedad, pobreza y desigualdad. Es decir, se insertan para obtener un ingreso que les permita adquirir bienes que sus padres no pueden comprar, desde bienes de consumo y entretenimiento, hasta los necesarios básicos para la escuela (útiles o zapatos).

En ambos casos se percibe en niños y niñas la convivencia de visiones que naturalizan el ingreso al trabajo productivo con visiones críticas. Las que son más evidentes en las niñas, especialmente frente a los costos personales del ingreso temprano al trabajo, tanto a nivel de la salud y el cuerpo, como en las posibilidades de seguir avanzando en el itinerario educativo. Los niños focalizan sus reclamos básicamente en la excesiva carga física. Las niñas en dejarlas decidir sobre su uso del tiempo.

El que la encuesta EANNA 2012 haya identificado un $10 \%$ de trabajo infantil en zonas rurales, y que en este estudio hayamos recogido que más de la mitad de los niños y más de un tercio de las niñas trabajan -teniendo claro que no podemos comparar una muestra representativa cuantitativa con datos de un abordaje cualitativo- nos conduce a plantear el subregistro que existe del trabajo productivo en la niñez en territorios rurales, pues cuando se establece un diálogo entre niños/as sobre el trabajo, van apareciendo experiencias laborales, de trabajo familiar por cuenta propia que se enmascara bajo la noción de "ayuda" o en un trabajo asalariado de ejecución familiar, que invisibiliza la participación infantil en el trabajo. Dicho subregistro representa una desigualdad 
social, puesto que impide entonces poder direccionar políticas públicas, por ejemplo, en el plano educativo, que integre y considere en escuelas y liceos rurales, la realidad de niños/as trabajadores, aun cuando sea ésta una inclusión estacional. Por otro lado, esta invisibilización impide que desde organismos públicos relacionados a trabajo e infancia se intencionen medidas para la protección de niños y niñas. Hoy la fruticultura goza de las ventajas de la participación de niños/as temporeros en cosechas, packing y trabajo a domicilio orientado a la exportación, pues es una integración informal y desregulada, con baja fiscalización. El costo para los niños temporeros es ocupar sus vacaciones escolares en el trabajo, negándose para ellos el ejercicio del derecho al descanso y al juego; y costos físicos, no identificados explícitamente en este estudio a nivel musculoesquelético (por la carga de los capachos o la altura de los árboles) y por la exposición al sol sin protección.

El trabajo de los niños temporeros, aun cuando es estacional (hasta 5 meses al año), está contemplado dentro de la categoría de trabajo peligroso, la cual a su vez está dentro de la tipificación de las Peores Formas de Trabajo Infantil (PFTI), pues reporta riesgos ergonómicos, se realiza a la intemperie, con exposición a pesticidas y al sol, cuestión que fue confirmada por los testimonios.

El estudio permite concluir que, desde temprana edad, se reproduce la división sexual patriarcal del trabajo en la niñez rural, tanto en los planos productivo como doméstico. En el primero la proporción de niños que trabajan es mayor que la de niñas rurales. Y cuando se trata del mercado asalariado agrícola las niñas no aparecen, si lo hacen en el trabajo agrícola a domicilio.
En el trabajo doméstico, los niños participan siendo los hijos mayores, en ausencia de sus madres o hermanas. En términos de variabilidad de tareas domésticas, se involucran en una diversidad de ellas, incluyendo el cuidado de otros/as, pero en menor intensidad que las niñas. Sin embargo, hay algunos trabajos domésticos en el que ningún niño participa, mostrando consistencia con los resultados de la encuesta EANNA, de concebir actividades domésticas como "naturalmente" femeninas, en este caso cocinar, lavar y tender ropa, y limpiar baños.

Desde la teoría de género, ya desde la infancia, los niños destacan por participar en actividades laborales vinculadas a lo público, con mayor valoración social y económica, e ingresos mayores que les permiten acceder al consumo presente y que podría situarlos en una posición de mayor poder que las niñas; y éstas por su parte, destinan sus energías y esfuerzos laborales a actividades que resultan menos involucradas a la individualidad y al poder (Hernando, 2005), como son las actividades reproductivas de la privacidad.

En relación a las representaciones del trabajo productivo desde la visión de la niñez, se concluye que existen posiciones ambivalentes $y$ en tensión. Niños/as en general no rechazan a priori su participación en el trabajo productivo. Las niñas son más críticas a la inserción temprana en el trabajo, sobre todo asalariado. Las opiniones de niños circulan entre concebir el trabajo como "divertido" versus otros que mencionan los abusos a los que están expuestos, así como las consecuencias físicas en sus cuerpos. Niños perciben que sus padres sobrevaloran su participación en el trabajo, pues los que no lo hacen "son flojos" a la mirada adulta masculina, tensionándose con la idea recogida 
en estudios previos (PNUD, 2008) que señala que la aspiración principal, especialmente de las madres en contextos rurales es la educación de sus hijos. Ahora bien, como el trabajo se hace en la estacionalidad, no hay deserción escolar, pero si atraso, y uso de las vacaciones en el trabajo. Sobre las representaciones presentes en torno a la participación en el trabajo doméstico, éste forma parte del quehacer cotidiano de niños y niñas, por lo que no es cuestionado. Sin embargo, en la infancia rural se comienza ya a gestar una repartición desigual material y simbólica por sexo, entre niños y niñas en el trabajo doméstico, concibiéndose éste como natural y parte de un mandato de género de las niñas.

En cuanto a la capacidad de negociación y toma de decisiones, se constató una baja participación de la niñez en un contexto de preeminencia de posiciones adultocéntricas. Las diferencias de género se presentan en situaciones de mayor privilegio infantil masculino para ausentarse de trabajos domésticos reproductivos que, más que negociados, son naturalizados por las familias y madres. En las niñas se presenta una búsqueda por negociar y decidir, no siempre con resultados favorables.

Finalmente, sobre las representaciones del futuro, los relatos siguen la tendencia que presenta la encuesta EANNA, en el sentido que niños se proyectan en mayor proporción en el futuro trabajando luego de terminar su escolaridad (en cualquier rama), formando una familia y teniendo hijos/as. Imaginario que no estuvo presente en los relatos de las niñas rurales. Todas se proyectan en la educación superior, estudiando carreras tradicionales y no tradicionales. Evidenciándose posiciones culturales más conservadoras en niños rurales y mostrando que las niñas, al igual que las mujeres rurales (en contraste con los hombres rurales) transitan hacia visiones más modernas, como lo han evidenciado otros estudios (Valdés, 2009; Caro, 2016). Aquí radicarían nuevos intereses de investigación, que aborden por ejemplo los mecanismos para alcanzar dichas aspiraciones futuras de niños y niñas.

\section{Bibliografía} Paidós.

Arendt, H. 1993. La condición humana. Madrid: Ediciones

Aries, P. 1987. El niño y la vida familiar en el antiguo régimen. Taurus. España.

Belvis F., Tarafa G. y Benach, J (2013). La medida estadística del trabajo infantil 2010-2012. Barcelona: Universitat Pompeu Fabra.

Beck, U. 1998. La sociedad del riesgo: Hacia una nueva modernidad. Barcelona: Ediciones Paidós Básica

Bourdieu, P. 1999. La miseria del mundo. Buenos Aires: Fondo de Cultura Económica.

2000. La dominación masculina. Barcelona: Anagrama.

Canales, M. 2005. "La nueva ruralidad en Chile: apuntes sobre subjetividad y territorios vividos". PNUD (Ed) Chile rural. Un desafío para el desarrollo humano. Santiago: PNUD. 33-41.

Caro, P. 2016. Relatos de cambio en tensión Trabajos, familias y género en valles del vino en Casablanca y Mendoza. Santiago: Ediciones RIL, Universidad Santo Tomás.

Casas, F. 2006. "Infancia y representaciones sociales". Revista Politica y Sociedad, 43(1): 27-42.

Castel, R. 1997. La metamorfosis de la cuestión social. Una crónica del salariado. Buenos Aires: Paidós.

2009. El ascenso de las incertidumbres. Trabajo, protecciones, estatuto del individuo. Buenos Aires: Fondo de Cultura Económica.

Castro, A. 2012. "Familias rurales y sus procesos de transformación: estudio de casos en un escenario de ruralidad en tensión". Revista Psicoperspectivas. Individuo y Sociedad, 11 (1), 180-203.

CEPAL. 2007. El aporte de las mujeres a la igualdad en América Latina y el Caribe. Santiago: CEPAL.

Consejo Nacional de la Infancia. 2015. Política nacional de 
Niñez y adolescencia. Sistema integral de garantías de Derechos de la niñez y adolescencia. Santiago.

Cussianovich, A. 2006. Ensayos sobre infancia, Sujetos de derechos y protagonistas. Lima: Ed. IFEJANT.

Gadamer, H-G. 1977. Verdad y Método. Salamanca: Ediciones Sígueme.

Gélis, J. 1994. "La individualización del niño". Aries P. y Duby,

G. Historia de la vida privada, Tomo IV. Barcelona: Taurus. 311-329.

Heller, A. 1970. Sociología de la vida cotidiana. Madrid: Editorial Península.

Hernández, R., Peña, A., Rubiano, Y. 2005. "Representaciones sociales del trabajo infantil”. Revista Orinoquia, (9)(1): 19- 29.

Hernández S., R. Fernández C.; y Baptista M. 2010. Metodología de la Investigación. México: Mc Graw Hill.

Hernando, A. 2005. "¿Por qué la historia no ha valorado las actividades de mantenimiento?". Treballs d'Arqueología № 11: 115-133.

Hirata, H. y Kergoat D. 1997. La división sexual del trabajo. Permanencia y cambio. Buenos Aires: Asociación Trabajo y Sociedad (Argentina), Centro de Estudios de la Mujer (Chile) y Piette del CONICET (Argentina).

Lamas, M. 2016. "Mujeres guerrerenses: feminismo y política". Revista Mexicana de Ciencias Políticas y Sociales. 226: 409-424.

Martuccelli, D. 2007. Las tres vías del individuo sociológico. Santiago: LOM.

Maureira, F. 2002. "Trabajo infantil. Algunas consideraciones desde la antropología”. Revista Austral de Ciencias Sociales ( $N^{\circ} 6$ ): 113-123.

MINDES. 2013. Resultados Encuesta de Actividades de niños, niñas y adolecentes (EANNA). Santiago.

Observatorio social. 2013. Libro de Códigos Encuesta de Actividades de Niños, Niñas y Adolescentes 2012: Base de datos Principal Parte I. Santiago: MINDES

OIT y Ministerio del Trabajo 2015. Crecer felices. Estrategia nacional para la erradicación del trabajo infantil y protección del adolescente trabajador 2015-2025. Santiago: OIT y MINTRAB.

PNUD. 2008. Desarrollo Humano En Chile Rural. Seis Millones Por Nuevos Caminos Santiago, Chile.

Rojas, J. 1996. Los niños cristaleros: trabajo infantil en la industria. Chile, 1880 -1950. Vol. X Colección Sociedad y Cultura. Santiago: DIBAM.

2010. Historia de la infancia en el Chile republicano,

1810-2010. Santiago: JUNJI.

Ruiz, J.I. (2003). Metodología de la investigación cualitativa. Bilbao: Universidad de Deusto.

Salazar, G. y Pinto J. 2002. Historia contemporánea de Chile. Volumen V. Niñez y juventud. Santiago: Ediciones LOM.

Salinas, R. 2001. "La historia de la infancia, una historia por hacer". Infancia y sociedad en Chile Tradicional Revista de historia social y de las mentalidades (5): 11-31.

Scott, J. 2008. Género e historia. México: FCE - Universidad Autónoma de la Ciudad de México.

Silva-Peña, I. et al. 2013. "Sentido de la Escuela para niños y niñas mapuche en una zona rural”. Polis. 12 (34): 243-258.

Silva U. y Damianovic N. 1998. Estudio exploratorio sobre trabajo infantil. Cuaderno de investigación $n^{\circ} 5$. Santiago: Dirección del Trabajo. Departamento de estudios.

Tarrés, M. L. 2004 (coordinadora). Observar, escuchar y comprender. Sobre la tradición cualitativa en la investigación social. México: FLACSO México- El Colegio de México.

Tarrés, M.L. 2012. "A propósito de la categoría de género: leer a Joan Scott". Revista Sociedade e Cultura, 15(2): 3-26.

Todaro, R. y Reyes N. 2009. Chile: relaciones de género en la industria vitivinícola, empleo y sistemas de cuidado. Santiago: CEM y Red Comercio, Género y Equidad en América Latina.

Valdés, X. 2009. "El lugar que habita el padre en Chile contemporáneo. Estudio de las representaciones sobre la paternidad en distintos grupos sociales". Revista Polis. Universidad Bolivariana, 8(23): 385-410.

Valdés, X. y Godoy, C. 2008. El lugar del padre: rupturas y herencias. Representaciones de la paternidad en grupos altos, medios y populares chilenos. Revista Estudios Avanzados. IDEA/ USACH. 6(9): 79-112.

Vela, F. 2004. Un acto metodológico básico de la investigación social: la entrevista cualitativa. Tarrés, M. L. (coordinadora). Observar, escuchar y comprender. Sobre la tradición cualitativa en la investigación social. México: FLACSO - El Colegio de México. 63-91. 
